\title{
HUBUNGAN PENGETAHUAN DAN SIKAP DENGAN PERILAKU PERAWAT DALAM PENGELOLAAN SAMPAH MEDIS DI RUMAH SAKIT DAERAH MANGUSADA KABUPATEN BADUNG
}

\author{
I Gusti Ngurah Gede Pradnyana ${ }^{1}$, I Made Bulda Mahayana ${ }^{2}$
}

\begin{abstract}
Activity hospitals generate waste in the form solid, liquid and gas that contain phatogen and harmful chemical. To improve the quality of services needs to be improved means to cope with waste. The purpose of this study is to determine the relationship of knowledge and the attitude to the behavior of nurses in the management of medical waste. This study used crosssectional study design with sample of 96 nurses who served in Emergency Unit and Operation Room. The data analysis using Chi-Square statistical test. Based on the results of the study, 61 people (63.5\%) had good knowledge, 38 people (39.6\%) had positive attitude and 59 people $(61.5 \%)$ had good behavior. The statistic result of research showed that there was relationship between knowledge with the behavior of nurses $(C C=76.011$, sig $=0.000)$ and attitude with the behavior of nurses $(C C=15.381$, sig-0.000). It can be conclude that there is a relantionship between knowledge with behavior of the nurse and relantionship between attitude with behavior of nurses in the management of medical waste. Hospital that is programmed in carrying out extension and training management of medical waste to nurse. Hospital to provide facilities and infrastructure that is adequate and available standard operating procedures for medical personnel about managemment of medical waste
\end{abstract}

Keywords: knowledge, attitude, behavior, medical waste

\section{PENDAHULUAN}

Rumah sakit adalah suatu sarana kesehatan yang menyelenggarakan pelayanan sebagai dalam ruang lingkup ilmu kesehatan masyarakat. Termasuk di dalamnya upaya pencegahan penyakit mulai dari diagnosis dini dan pengobatan yang tepat, perawatan intensif dan rehabilitasi orang sakit sampai tingkat penyembuhan optimal ${ }^{1}$. Menurut Kepmenkes RI Nomor: 7 Tahun 2019 Tentang Kesehatan Lingkungan Rumah Sakit sebagai sarana pelayanan kesehatan, tempat berkumpulnya orang sakit maupun orang sehat sehingga menjadi tempat penularan penyakit ${ }^{2}$. Aktivitas rumah sakit menghasilkan sejumlah hasil samping berupa limbah, baik limbah padat, cair, dan gas yang mengandung kuman patogen, dan zat-zat kimia yang berbahaya. Untuk meningkatkan mutu pelayanan perlu ditingkatkan sarana untuk mengatasi limbah tersebut ${ }^{3}$. Pengelolaan limbah medis padat perlu ditangani secara benar dan aman, penanganan limbah medis padat harus segera dibenahi untuk menjamin kesehatan dan keselamatan tenaga kerja maupun orang lain yang berada di lingkungan rumah sakit. 
Kebijakan sesuai manejemen kesehatan dan keselamatan kerja dengan melaksanakan kegiatan pengelolaan dan monitoring limbah rumah sakit sebagai salah satu indikator penting yang perlu diperhatikan ${ }^{4}$.

Rumah Sakit Daerah Mangusada merupakan rumah sakit yang telah melakukan aktifitas pengelolaan limbah padat, pengelolaan limbah padat dilakukan mulai dari pemisahan, penampungan, pengangkutan dan pembuangan atau pemusnahan. Penghasil limbah padat medis terbanyak yaitu diruangan operasi dan ruang unit gawat darurat. Sampah medis yang dihasilkan oleh Rumah Sakit Daerah Mangusada selama Tahun 2019 sebanyak $71.628,17 \mathrm{~kg}$ dan rata-rata per harinya kurang lebih196,24 kg.

Proses pemisahan limbah padat di rumah sakit dilakukan oleh petugas kesehatan khususnya perawat yang berada di setiap unit pelayanan. Pengolahan limbah padat selanjutnya dilakukan oleh petugas kebersihan di rumah sakit. Hasil studi pendahuluan yang memperoleh hasil yaitu untuk mencegah adanya kecelakaan kerja dan mengurangi bahaya infeksi nosokomial belum cukup dengan menyediakan pembedaan tempat sampah medis maupun non medis di ruang perawatan karena masih adanya pemilahan sampah yang belum baik oleh perawat atau masih tercampur sampah medis dan non medis.

\section{METODE PENELITIAN}

Penelitian ini merupakan jenis penelitian observasional dengan pendekatan cross-sectional, yaitu menjelaskan hubungan korelatif antara variable bebas (pengetahuan dan sikap) dan variable terikat (pengelolaan sampah medis) pada perawat. Penelitian dilaksanakan di Rumah Sakit Daerah Mangusada Kabupaten Badung. Dalam penelitian ini yang menjadi populasi terjangkau adalah perawat yang bertugas di Instalasi Gawat Darurat dan ruang operasi yaitu sebanyak 111 orang terdiri dari 68 orang di IGD dan 43 di ruang oprasi.

Untuk analisis data menggunakan analisis univariat berfungsi untuk meringkas data hasil pengumpulan data karakteristik sedemikian rupa sehingga kumpulan data tersebut dapat diubah menjadi informasi yang berguna 5 Analisis bivariat dipergunakan untuk mengetahui hubungan pengetahuan dan sikap dengan perilaku perawat dalam pengelolaan sampah medis. Analisis bivariat akan mempergunakan uji statistik Chi Square. ${ }^{5}$ 


\section{HASIL}

\section{Hubungan pengetahuan dengan perilaku responden}

Tabel 1

Hubungan Pengetahuan Dengan Perilaku Perawat Dalam Pengelolaan Sampah Medis Di RSD Mangusada Kabupaten Badung

\begin{tabular}{lcrrrrrr}
\hline Pengetahuan & \multicolumn{2}{c}{$\begin{array}{c}\text { Perilaku } \\
\text { Kurang }\end{array}$} & \multicolumn{2}{c}{$\begin{array}{c}\text { Perilaku } \\
\text { Baik }\end{array}$} & \multicolumn{2}{l}{ Total } & \\
& $\mathrm{N}$ & $\%$ & $\mathrm{~N}$ & $\%$ & $\mathrm{~N}$ & $\%$ & \\
& 34 & 97,1 & 1 & 2,9 & 35 & 100 & $\mathrm{CC}=76,011$ \\
Kurang & 3 & 4,9 & 58 & 95,1 & 61 & 100 & sig $=0,000$ \\
Baik & $\mathbf{3 7}$ & $\mathbf{3 8 , 5}$ & $\mathbf{5 9}$ & $\mathbf{6 1 , 5}$ & $\mathbf{9 6}$ & $\mathbf{1 0 0}$ & \\
\hline Total & & & & & & &
\end{tabular}

Pada tabel 7 didapatkan hasil bahwa responden dengan pengetahuan kurang dengan perilaku kurang sebanyak 34 orang $(97,1 \%)$ dan pengetahuan kurang perilaku baik sebanyak 1 orang (2,9\%). Sedangkan responden dengan pengetahuan baik perilaku kurang sebanyak 3 orang $(4,9 \%)$ dan pengetahuan baik perilaku baik sebanyak 58 orang $(95,1 \%)$

Hasil analisis statistik dengan mempergunakan uji Chi Square diperoleh nilai continuity correction (CC) sebesar 76,011 dengan nilai signifikansi sebesar 0,000 menunjukkan bahwa adanya hubungan yang signifikan antara pengetahuan dengan perilaku perawat dalam pengelolaan sampah medis di RSD Mangusada Kabupaten Badung. 


\section{Hubungan sikap dengan perilaku responden}

Tabel 2

Hubungan Sikap Dengan Perilaku Perawat Dalam Pengelolaan Sampah Medis Di RSD Mangusada Kabupaten Badung

\begin{tabular}{lccccccc}
\hline Sikap & $\begin{array}{c}\text { Perilaku } \\
\text { Kurang }\end{array}$ & \multicolumn{2}{c}{$\begin{array}{c}\text { Perilaku } \\
\text { Baik }\end{array}$} & \multicolumn{2}{c}{ Total } & \\
& $\mathrm{N}$ & $\%$ & $\mathrm{~N}$ & $\%$ & $\mathrm{~N}$ & $\%$ & \\
\hline Negatif & 32 & 55,2 & 26 & 44,8 & 58 & 100 & $\mathrm{CC}=15,381$ \\
Positif & 5 & 13,2 & 33 & 86,8 & 38 & 100 & sig=0,000 \\
\hline Total & $\mathbf{3 7}$ & $\mathbf{3 8 , 5}$ & $\mathbf{5 9}$ & $\mathbf{6 1 , 5}$ & $\mathbf{9 6}$ & $\mathbf{1 0 0}$ &
\end{tabular}

Pada tabel 8 didapatkan hasil bahwa responden dengan sikap negatif perilaku kurang sebanyak 32 orang $(55,2 \%)$ dan yang memiliki sikap negatif perilaku baik sebanyak 26 orang $(44,8 \%)$. Sedangkan responden dengan sikap positif perilaku kurang sebanyak 5 orang $(13,2 \%)$ dan yang memiliki sikap positif perilaku baik sebanyak 33 orang $(86,8 \%)$.

\section{PEMBAHASAN}

\section{Hubungan pengetahuan dengan}

perilaku perawat dalam pengelolaan sampah medis di RSD Mangusada

Hasil penelitian pada tabel 7 didapatkan hasil bahwa responden dengan pengetahuan kurang dengan perilaku kurang sebanyak 34 orang $(97,1 \%)$ dan pengetahuan kurang perilaku baik sebanyak 1 orang $(2,9 \%)$. Sedangkan responden dengan
Hasil analisis statistik dengan mempergunakan uji Chi - Square diperoleh nilai continuity correction (CC) sebesar 15,381 dengan nilai signifikansi sebesar 0,000 menunjukkan adanya hubungan yang signifikan antara sikap dengan perilaku perawat dalam pengelolaan sampah medis di RSD Mangusada Kabupaten Badung. pengetahuan baik perilaku kurang sebanyak 3 orang $(4,9 \%)$ dan pengetahuan baik perilaku baik sebanyak 58 orang $(95,1 \%)$. Berdasarkan hasil penelitian tersebut diketahui bahwa sebagian besar responden memiliki pengetahuan baik perilaku baik sebanyak 58 orang $(95,1 \%)$

Penelitian Riyanto (2013) Tingkat pengetahuan erat kaitannya dengan 
pendidikan, semakin tinggi tingkat pendidikan maka tingkat pengetahuan perawat juga akan semakin baik dalam pengelolaan sampah medis. Seseorang yang berpendidikan lebih tinggi akan mempunyai pengetahuan yang lebih luas dibandingkan dengan seseorang yang tingkat pendidikannya lebih rendah.

Faktor pengetahuan tentang sampah sangat penting untuk ditanamkan pada setiap perawat yang akan melakukan pembuangan sampah medis. Salah satu cara meningkatkan pengetahuan dengan cara memberikan penyuluhan dan pelatihan. Penelitian Maulana (2012), menunjukkan kebutuhan akan program pelatihan untuk berbagai tingkat staf di rumah sakit dari administrator, manajer, dokter, perawat sampai petugas penanganan dan pemeliharaan sampah medis di rumah sakit.

Hasil pengetahuan responden yang kurang baik dalam pengelolaan sampah medis dapat dipengaruhi oleh banyak stimulus. Kurangnya pengetahuan perawat dalam pengelolaan sampah, memilah sampah sebelum dimasukan ke dalam tempat sampah sesuai jenis kantong sampah berpengaruh dalam tindakan perawat dalam pengelolaan sampah medis ${ }^{8}$. Faktor pengetahuan dan sikap merupakan faktor domain terjadinya perilaku maka upaya adanya pelatihan, pengawasan, peneguran maupun menyediakan sarana prasarana dalam hal ini menambah jumlah tempat sampah merupakan beberapa upaya untuk memperbaiki perilaku perawat dalam mengelola sampah ${ }^{9}$.

Penelitian ini sejalan dengan penelitian Maharani (2017) yang menyatakan bahwa ada hubungan antara pengetahuan dan perilaku dalam pengelolaan limbah medis.

\section{Hubungan sikap dengan perilaku perawat dalam pengelolaan sampah medis di RSD Mangusada}

Sikap seseorang meliputi adanya proses menerima dan rangsangan atau stimulus, menanggapi pertanyaan dengan cara memberi pendapat, menilai dengan positif objek yang diketahui dan bertanggung jawab atas resiko yang muncul. Sikap seseorang dipengaruhi beberapa faktor meliputi pendidikan, media masa kejiwaan, emosi pengalaman pribadi serta lembaga pendidikan (Notoatmodjo 2010).

Upaya pengelola sampah yang dapat mempengaruhi sikap seorang perawat dalam melakukan pembuangan sampah medis diharapkan adanya pengawasan maupun peneguran jika terjadi sikap yang salah dan adanya petugas yang melakukan pengecekan keadaan sampah di setiap ruangan agar tidak 
terjadi penumpukan sampah. Sikap akan berdampak pada perilaku setiap perawat, dengan sikap yang baik diharapkan akan menimbulkan perilaku yang baik walaupun tidak selalu.

Menurut Catherine (2016), peran lembaga pendidikan keperawatan untuk mengajarkan prinsip-prinsip standar precaution yang di dalamnya terdapat prinsip pengelolaan limbah infeksius dalam hal ini diklat keperawatan informal di lingkungan rumah sakit saat ini belum memiliki perpustakaan yang memadai dalam penyediaan buku terkait kewaspadaan standar dan belum adanya jadwal pelatihan penanganan infeksi nosokomial secara berkala dari pihak rumah sakit.

Tenaga kesehatan sebagai penghasil limbah medis padat memiliki risiko yang besar terhadap kecelakaan dan penyebaran penyakit sehingga sebagai orang pertama yang berkontak langsung dengan limbah medis dan penghasil limbah medis seharusnya memiliki pengetahuan dan sikap yang baik tentang pengelolaan limbah medis padat agar menjadi pencegah dari terjadinya risiko yang memungkinkan terjadi akibat limbah medis padat seperti tertusuk jarum suntik yang telah terkontaminasi HIV atau hepatitis, sehingga HIV dan hepatitis tersebut dapat menyebar ${ }^{10}$.
Penelitian ini sejalan dengan penelitian Fahriyah (2015) yang menyatakan bahwa ada hubungan antara sikap dengan perilaku perawat dalam pengelolaan limbah medis.

\section{SIMPULAN DAN SARAN}

Berdasarkan hasil penelitian di RSD Mangusada tentang pengelolaan sampah medis, maka dapat disimpulkan ada hubungan pengetahuan dengan perilaku perawat dalam pengelolaan sampah medis di RSD Mangusada dan ada hubungan sikap dengan perilaku perawat dalam pengelolaan sampah medis di RSD Mangusada

Saran yang dapat disampaikan pihak RSD Mangusada melalui PKRS agar melaksanakan penyuluhan dan pelatihan tentang pengelolaan sampah medis kepada perawat dan tenaga kesehatan lainnya sesuai program yang ada rumah sakit agar menyediakan sarana dan prasana pengelolaan sampah medis yang lebih memadai sesuai standar kesehatan dan tersedianya standar operasional prosedur bagi tenaga kesehatan terkait dengan pengelolaan sampah medis 


\section{DAFTAR PUSTAKA}

1. Adisasmito. Materi Pokok

Manajemen Pelayanan Umum.

(Grafindo Persada, 2009).

2. RI, P. Peraturan Menteri Kesehatan

Republik Indonesia No. 7 Tahun

2019. Tentang Kesehatan Lingkungan

Rumah Sakit. (Kementrian Kesehatan

RI, 2019).

3. Adisasmito. Sistem Manajemen

Lingkungan Rumah Sakit. (Grafindo

Persada, 2007).

4. Adhitama. Manajemen Administrasi

Rumah Sakit. (Golek Buku, 2006).

5. Arikunto. Prosedur Penelitian Suatu

Pendekatan Praktek. (PT. Rineka

Cipta, 2006).

6. Riyanto. Analisis Pengaruh Earning

Per Share (EPS). (Salemba Empat, 2013).

7. Maulana. Hubungan, Sikap dan

Ketersediaan fasilitas dengan Praktik

Petugas Pengumpul Limbah Medis di

RSUD Abdul Wahab Ajahranie

Samarinda. J. Ilm. Kesehat. Masy.

Univ. Hasanuddin Makasar (2012).

8. Sembiring. Hubungan Tingkat

Pengetahuan Dengan Tindakan

Perawat Dalam Pengelolaan Sampah

Medis di RSU Sembiring Deli Tua

Tahun 2018. J. Kesehat. Masy. dan
Gizi, Fak. Kesehat. Masy. (2018).

9. Sholikah. Hubungan Pengetahuan dan Sikap dengan perilaku dalam pembuangan sampah medis di RS PKU Muhammadiyah Yogyakarta. $J$. Ilm. Kesehat. Masy. 6, (2012).

10. Maharani. Pengetahuan dan Sikap

Tenaga Kesehatan Terhadap Pengelolaan Limbah Medis Pada Salah Satu Rumah Sakit Di Kota Bandung. Falkultas Kedodokteran Univ. Padjadjaran (2017).

11. Notoatmodjo, S. Promosi Kesehatan Teori dan Aplikasi. (Rineka Cipta, 2010).

12. Catherine. Mothers Employment, Marital Status, and Educational Level on Students Academic Achievementin Business Studies. Asia Pacific J. Multidiscip. Res. 4, (2016).

13. Fahriyah. Pengetahuan dan sikap dengan perilaku perawat dalam pemilahan dan pewadahan limbah medis di RSUD Dr.H Soemarno Sosroatmodjo Kuala Kapuas. J. Publ. Kesehat. Masy. Indones. 3, (2015). 